\title{
SLOTERDIJK Y HEIDEGGER: A PRopósito de UN LIBRo de CARLA CORduA ${ }^{1}$
}

\author{
Adolfo Vásquez Rocca \\ Universidad Andrés Bello UNAB \\ Universidad Complutense de Madrid \\ adolfovrocca@gmail.com
}

\begin{abstract}
D1. El libro de claro designio hermenéutico recientemente publicado 11 por Carla Cordua, -Sloterdijk y Heidegger: La recepción filosófica (2008)se concentra en las declaraciones de Peter Sloterdijk en torno a la obra temprana de Martin Heidegger para -desde esta acotada perspectiva- dar cuenta de la compleja recepción filosófica que la obra de Heidegger ha tenido entre los pensadores alemanes que le preceden.
\end{abstract}

La profesora Cordua analiza el caso de Peter Sloterdijk, quien a la vez retoma y critica a su antecesor, Martin Heidegger. Aun cuando el término 'maestro' no sea el que más convenga para caracterizar a Heidegger en relación con Sloterdijk, claramente entre ambos autores hay preocupaciones y problemas filosóficos compartidos; de allí que se justifique relacionarlos en una línea de sucesión. Además, Sloterdijk ha declarado que Heidegger -sin lugar a dudas- se encuentra en la primera línea de la filosofía europea, "quizás el único en nuestro siglo que, mirando con cierta amplitud, podría aspirar a codearse con Platón, San Agustín, Tomás de Aquino, Spinoza, Kant, Hegel y Nietzsche" (Sloterdijk y Heinrichs 2004, p. 104). Sin embargo, Sloterdijk no repara en objetar a Heidegger el haberse dejado arrastrar por la marea de la política, comprometiéndose con el nacionalsocialismo -cuestión tratada exhaustivamente por una copiosa literatura previa-, criticándole además por sus preferencias localistas, provincianas y nacionalistas, todas las cuales le habrían impreso un talante anacrónico, no solo a su personalidad, sino fundamentalmente a sus doctrinas y a sus obras.

Pese a todo, la relación de Heidegger y el nacionalsocialismo puede ser entendida como de hecho lo intenta Sloterdijk a través de un concepto heideggeriano -la "errancia"- sobre la que se profundizará luego. El punto aquí es que Sloterdijk califica a Heidegger de una suerte de "Empédocles político", el filósofo presocrático que según la tradición saltó al volcán Etna para probar su linaje divino. Para explicar

1 El presente estudio crítico forma parte del Proyecto de Investigación $\mathrm{N}^{\circ}$ DI-10-09/JM -UNAB “Ontología de las distancias en Sloterdijk, hacia una teoría antropotécnica de las comunicaciones”. Dirección de Investigación, Universidad Andrés Bello- Fondo Jorge Millas 2009, Facultad de Humanidades y Educación UNAB. 
este hecho, Sloterdijk, según la referencia de la profesora Cordua, nos dice que el silencio de Heidegger: "Después de 1945 solo puede ser comprendido como un gesto de vergüenza empedocleana; si el cráter no devora al sabio sino que lo devuelve, condenándolo a la ignominia de la sobrevivencia, entonces el sujeto recibirá una lección importante de ello, pero la humillación es demasiado profunda como para que pueda ser discutida en público. Solo al borde del cráter se aclara el sentido de la frase: Pensar en grande significa errar en grande" (Cordua 2008, p. 31).

2. Heidegger impresiona a Sloterdijk por su incomprensión del mundo moderno, incomprensión, piensa, ligada estrechamente a su rechazo de la racionalidad técnica, su conservadurismo político y su apego a la tierra (Cordua 2008, p. 28). De allí que el claro - die Lichtung- de Heidegger sea una metáfora forestal, propia del imaginario filoagrario (Vásquez Rocca 2008b) que no evoca el ámbito de las discusiones ciudadanas, entre las que cabe considerar, por ejemplo, el mercado. Por ello, Heidegger no avanzó hasta la ciudad y su centro, hasta la plaza, el ágora o el foro, resultándole aún más ajeno aquello a que se llega trascendiendo la ciudad: el espacio político del Estado, las relaciones internacionales, el cosmopolitismo moderno. Heidegger, como el último cerebro de la era agraria, reaccionó contra la modernidad industrializada. "Nunca entendió ni supo apreciar la navegación ultramarina, ni el capital, ni los medios de comunicación", que son precisamente los temas que hoy ocupan a Sloterdijk (2007). Así, en la perspectiva de Sloterdijk, el rechazo heideggeriano de la antropología no solo separa a la filosofía de fuentes de información indispensables, sino que, peor aún, es una actitud que excluye la posibilidad de que el pensamiento pueda nutrirse del rico saber empírico acumulado en las ciencias especiales.

De este modo, como se puntualiza en el libro, Sloterdijk critica a Heidegger su concepto de mundo y particularmente el modo de concebir la entrada del hombre en él. Según Heidegger, somos arrojados en el mundo, cosa ominosa que tiene el acento de un un oscuro castigo; de este modo, el mundo moderno, hogar largamente preparado por la historia de lo monstruoso violento y arbitrario (das Ungeheure), es el lugar en el que luchan los gigantes poderes impersonales ligados a la técnica apocalíptica. "En el universo del conocimiento moderno predominan los bastidores, los suelos dobles, los panoramas, las imágenes engañosas, los gestos torcidos, los sentimientos secretos, los motivos ocultos, los cuerpos envueltos" (Sloterdijk 2003a, t. II, p. 604).

Sloterdijk pasa de la definición de Heidegger del hombre como ser arrojado al mundo y ser para la muerte, hasta la visión muy distinta de Lévinas de la muerte como una invitación a una nueva trascendencia a partir de una relación radicalmente inédita de apertura ética hacia el otro y hacia lo Otro, cuestión que se entrevera con la conciencia trágica, con la desesperanzada lucidez provocada por las dos guerras mundiales, por Hiroshima, por Auschwitz, ante todo, por el terrorismo y por el contraterrorismo global, cuya lógica, como ha mostrado en Temblores de Aire (Vásquez Rocca 2008a) es: "hacer irrespirable el ambiente del otro; por la amenaza del exterminio total"; algo que ha inspirado su idea del filósofo como aquel que ejerce la vigilia o la vigía del mundo. 
El crecimiento del conocimiento y de la técnica no puede seguir siendo interpretado -señala Sloterdijk - como pretendía Heidegger, quien continuaba entendiéndolo, después de dos siglos y medio de metafísica y técnica europeas, como los envíos del destino a la errancia de los hombres. La errancia (die Irre), la inevitable mixtura de la verdad con el error y el ocultamiento, propia de la condición de la existencia humana, es la forma dinámica con la que la existencia inauténtica se desplaza sin fin. La errancia es entendida como el extravío de la humanidad durante la época moderna, que, olvidando el ser, confía su existencia y su mundo a la técnica (Cordua 2008, p. 110). Sloterdijk le reconoce a Heidegger que "para [él] era evidente que la errancia era duradera y grande” (Sloterdijk 2001, p. 214; citado por Cordua 2008, p. 110).

La verdad no se descubre inocuamente y sin batalla, sino solo después de triunfar batallando contra sus antecesoras, que la enmascaran y se le oponen. La historia de la verdad es concebida por Heidegger, a partir del estado de cosas del año 1946, como la quemazón de un hilo conceptual combustible extendido desde Atenas a Hiroshima (Cordua 2008, p. 113); el cual, como puntualiza Sloterdijk, sigue hasta los laboratorios de ingeniería genética (Gentechnik) actuales.

Para Heidegger, receloso de la técnica, el pensamiento auténtico permanece totalmente vinculado al paradigma de un mundo en crecimiento, tal y como es experimentado por un campesino. Heidegger sería de este modo el último metafísico de la vieja Europa. Su concepción de un mundo en crecimiento comporta las ideas de productividad y progreso vinculadas indefectiblemente a los poderes de una técnica apocalíptica. Pero ¿de qué producto y progreso se trata? El producto en cuestión es aquí, ante todo, el hombre mismo, y el progreso, su cometido de guardar el Ser y corresponderle como su pastor. Lo que hay en juego en todo esto es la expresión de un problema antiquísimo, a saber, el de la cría y domesticación del hombre por el hombre; un problema en el que han estado involucrados, por referirse solo al gremio, todos los filósofos, y que podría denominarse como la disputa por la antropogénesis, esto es, la lucha encarnizada por obtener un derecho procreador y tutorial sobre el hombre. Es a partir del intento heideggereano de dilatar el imaginario agrario del mundo que se puede barruntar el porqué de la aversión de Heidegger hacia la democracia, el capitalismo, el socialismo, el humanismo y la técnica industrial en curso.

Heidegger advierte la sociedad de la democracia liberal y capitalista como el fin de la comunidad en torno a la tierra. En este sentido, la afirmación de Sloterdijk, según la cual Heidegger es el último cerebro de la era agraria, trae consigo la concepción de la política clásica de acuerdo con la cual los hombres eran obras de hombres gestados en el seno de la comunidad, a la vez que unidos a la tierra por un cordón umbilical llamado tradición. En este proceso histórico de conservación del hombre por el hombre, la metafórica agraria concebía a cada nueva generación de hombres como el producto del orden y rotación inmemorial de siembras y cosechas. En estos puntos decisivos, Sloterdijk confronta la posición de Heidegger. Cuando Sloterdijk refiere a la condición interior compartida del hombre, se separa decididamente del pensamiento heideggeriano (Cordua 2008, p. 174). La interioridad del hombre no equivale a mantenerse fiel y apegado al lugar del nacimiento. Para Sloterdijk, hoy estamos dominados por un romanticismo de lo abierto que nos inclina a desconocer la importancia 
que tienen para nosotros los espacios circunscritos, los muros y arcas de ciudad desde los cuales avanzamos hacia lo más amplio y abarcante. Heidegger -a diferencia de Sloterdijk - tampoco sabe decir ni una palabra acerca de lo amable que es investigar, viajar [...]; tampoco dice nada sobre "establecer amistades, iniciar empresas, hacer ejercicios, ni acerca de traducir o enlazar tradiciones. En esta actitud, [Heidegger] es solo uno de los muchos críticos de la modernidad que guardan un silencio falto de experiencia y lleno de odio cuando se trata de hablar sobre nuestras mejores fuerzas: el bricolaje, el cruzar razas de plantas y animales, la clasificación, la transacción y todo el espectro de las operaciones constitutivas de la ciencia como profesión y de la formación de comunas como plástica social. La profundidad de Heidegger carece de amplitud" (Sloterdijk 2001, p. 54; citado por Cordua 2008, p. 175).

3. Como se aprecia, a juicio de la autora, un estudio de la evaluación crítica de Heidegger formulada en la obra de Sloterdijk debe proceder detalladamente, diferenciando con cuidado la deuda que reconoce y de la que se apropia parcialmente, de aquello que separa y hasta opone a ambos pensadores. Así, para cumplir esta tarea examina la relación entre ambos autores sin simplificarla ni deformarla, lo que constituye el mérito de esta obra. Para ello, expone ciertos aspectos del legado heideggeriano y algunas de las tesis centrales de Sloterdijk, puntualizando caso a caso si esta relación es la de la profundización o la de la crítica. Sloterdijk piensa en la línea de Heidegger, aunque generalmente lo haga contra Heidegger.

Situado pues en esta perspectiva crítica, Sloterdijk describe de manera paradójica su relación con Heidegger: 'con él' - 'contra él', 'íntimo y distante'. De este modo, aunque Sloterdijk admite una deuda con Heidegger, en quien reconoce a alguien próximo que ha hecho un aporte decisivo al pensamiento moderno, oponiéndose a la metafísica, al idealismo y al logicismo, él no deja nunca de ser un pensador original, independiente y hasta inclasificable, un profundo conocedor de la tradición europea, que a la vez honra y critica implacablemente. En este sentido, la filosofía de Sloterdijk es sin duda un proyecto personal que no se excusa por tener este carácter, y que, aunque tiene presente y respeta la tradición del pensamiento, se siente estrechamente ligado a la literatura y filosofía de su tiempo. Por ello, la autora sostiene con acierto que la obra de Heidegger es solo una de las fuentes en las que Sloterdijk busca aliento y apoyo para desarrollar sus propias tesis.

Ya en el primer volumen de Esferas, publicado en alemán en 1998, Sloterdijk (2003b) estudia entre otros muchos asuntos, el tratamiento que Ser y tiempo da a la cuestión del espacio de la existencia. Sloterdijk critica la insuficiencia de lo que Heidegger ofrece a este respecto: concentrada en la temporalidad de la existencia, la obra se limita a plantear la pregunta por el dónde de la existencia, pero abandona prontamente el tema para seguir con su asunto principal, que es el análisis del existente solitario, según Sloterdijk.

Pocos intérpretes de Heidegger han descubierto, indica Sloterdijk, que bajo el sensacional título programático de Ser y tiempo se esconde también un tratado 
germinalmente revolucionario sobre Ser y espacio. El encanto de la analítica existencial del tiempo heideggeriana ha hecho pasar por alto el hecho de que está anclada en una correspondiente analítica del espacio, así como que ambas, a su vez, se fundan en una analítica existencial del movimiento. De ahí que sobre la doctrina de Heidegger de la temporalización e historicidad -la ontocronología- haya una copiosa bibliografía e investigación sobre su teoría del movimiento u ontocinética, y sobre sus planteamientos germinales en torno a una disposición originaria del espacio u ontotopología, prácticamente nada. Por ello Sloterdijk sostiene que Heidegger pasa demasiado rápidamente de la pregunta por el 'dónde' a la pregunta por el 'quién', perdiendo la oportunidad de explorar la inmensa diversidad de los universos de la espacialidad humana. Esta centralidad y diversidad de significados de los espacios habitados constituye, en cambio, el propósito principal de la obra sistemática de Sloterdijk en Esferas.

Sloterdijk, como certeramente indica la profesora Cordua, da muestras de sentirse incómodo e inseguro con el carácter formal de la expresión 'ser-en-el-mundo' tomada de Heidegger. ¿Dónde está el hombre? Cuando se quiere describir o referirse al lugar primero, auténtico y verdadero, en el cual están o se encuentran los hombres, piensa Sloterdijk, no conviene la fórmula heideggeriana que comete un error conceptual al insertar al habitante de manera inmediata en el mundo como si fuese de por sí un lugar hogareño y no la exterioridad despojada.

Solo en las catástrofes, cuando todas las habitaciones humanas han colapsado y se abre la desnuda exterioridad, se encuentran los mortales expuestos al interior de la nada (hineingehalten in das Nichts), como dice Heidegger. Pero, por lo general, vale para ellos la regla de que su estadía transcurre en un espacio dividido. Y rige el principio de las esferas que se aglutinan unas con otras.

4. A Sloterdijk le había sido útil el sentido existencial del In-sein (ser o estaradentro) de Heidegger, principalmente, para caracterizar a la comunidad o 'sociabilidad' de las personas, la cual es primordialmente para él una esfera animada por una inspiración o alma compartida. El ser-con otros no es algo que se agregue desde fuera a los integrantes del grupo que vive la misma vida en el mismo lugar. In-sein sería lo propio, próximo, habitual y confiable, que nos resulta íntimo por ser también lo propio, íntimo y habitual de los demás que son con-nosotros, esto es, por ser compartido y constantemente comunicado entre sus miembros. Ser-con es haberse desarrollado como intimidad dentro de una comunidad que vive de una inspiración común familiar y transmisible. Esencialmente se trata del modo en que se le da el mundo, lo intramundano y la vida humana a quien tiene la condición del ser-en-el-mundo, el cual siempre me incluye juntamente con los otros del caso. El estar-dentro significa, en consecuencia, un compromiso cabal no solo de las circunstancias de todos y de cada uno, sino quiere decir, en primer lugar, un compromiso de los recesos más íntimos de la identidad de todos y de cada cual. Sin embargo, esto es algo que Heidegger no vio de la misma manera debido a su concepción del carácter solitario del Dasein. Pues “estar-dentro quiere decir coincidir con los más próximos en la experiencia común de 
la existencia en ese mundo compartido". De lo que se sigue que la intimidad no debe ser pensada de manera exclusivista o individualista, pues es, al menos en la aplicación sloterdijkiana, precisamente aquello en que los individuos que son juntos coinciden; "lo común que les permite entenderse, actuar juntos y mantenerse relacionados simpática o conflictivamente, esa comunalidad de lo que es propio de todos y de cada cual" (Cordua 2008, pp. 185-186).

Por tanto, para Sloterdijk lo característico del hombre es ser o estar en círculos definidos cualitativamente. La cercanía o vecindad de nuestra estancia habitual, que compartimos con unos u otros, donde estamos siempre con animales y con cosas, resulta apenas perceptible para nosotros, debido a que pertenecemos a ella habitualmente; solo se nos hace presente cuando la perdemos. Las relaciones de proximidad son autógenas, esto es, creadoras de espacios internos e íntimos para quienes participan en ellas repartiéndolas con los demás. Estos ambientes de la intimidad están, a su vez, situados en espacios más vastos o macroesferas que, aunque los contienen, no tienen parte en el calor y la protección que ofrecen los microespacios.

Sloterdijk examina los microespacios antiquísimos que llama "burbujas”, "invernáculos sin paredes de la solidaridad esférica", "formas de auto cobijo", "construcción de nichos", "endosferas"-frente a exosferas-, "totalidades integradoras", formas de "creación local de mundo", existencias en un "ser-ahí-en-un-espacio-compartido", "formas inclusivas", agrupamientos "uteromiméticos" y "cobijantes".

El destino de todos los sistemas metafísicos de inmunidad se decide, según Sloterdijk, frente a la cuestión de si los seres abiertos al gran mundo, los seres humanos de la época de imperios y ciudades, consiguen dar plenamente el salto del autocobijo colectivo en comunidades ciudadanas fortificadas al autoaseguramiento individual, más allá de patrias ocasionales (Sloterdijk 2004, p. 309).

Fue un logro de las grandes culturas haber elevado la asimilación interior del exterior estresante a un nivel históricamente mantenible a largo plazo. Potencias mundiales que lograron ser algo más que improvisaciones militares fueron aquellas que consiguieron domesticar los monstruos inmensos de la exterioridad -la muerte, el mal, la peste, lo extraño, lo desmedido- y traspasar a las generaciones siguientes, como hábito cultural, sus éxitos en esa domesticación. Aunque ninguno de esos monstruos pierde nunca del todo su pavorosa capacidad de intranquilizar, en las grandes cosmovisiones se los convierte, sin embargo, en estresores internos y se los pone dialécticamente al servicio del todo (Sloterdijk 2003b, p. 149). Las grandes culturas saben convertir en negatividades provechosas la exterioridad destructora. Utilizan lo monstruoso como hormonas de crecimiento para elevarse de formas microesféricas a macroesferas.

El ser humano ha de esperar y sobrevivir a las separaciones de sus próximos. Ya en las formas humanas de vida más antiguas, las hordas arcaicas, la muerte se impone como apremio a dirigir la mirada a los muertos más queridos. Cuando la vista del cadáver y el pasmo que advierte en el lugar vacío adquieren formas rituales, todo ello se organiza como recuerdo; de él provienen los cultos a los antepasados y a los muertos; ellos inducen el originario estrés metafísico que pesa sobre los 
grupos humanos ya en los estadios tempranos de la hominización (Sloterdijk 2004, p. 149). Se reconoce que esos cultos tienen siempre un sentido esferológico creador de espacio, de inclusión restauradora, de reparación de la esfera psíquica rota por la desaparición del otro importante, de retorno a la normalidad cósmica, a la íntima burbuja de coexistencia (Sloterdijk 2004, p. 150) -en este caso ritual y simbólica.

Sloterdijk desarrolla la idea de la muerte como raíz de la constitución y devenir de los sujetos, yendo más allá de su antecedente en Heidegger; la idea de muerte, se podría decir retrospectivamente: la muerte local, la muerte global, la muerte personal, la muerte a la cual corremos todos, es el punto de partida para examinar la génesis de las macroesferas, lo que en bajo otro registro puede llamarse lo global.

La muerte también atestigua nuestra irreductible historicidad. El hombre, sujeto de alta permeabilidad, disponiendo de innumerables horas, protagonista de proezas e intempestivas historias, es un ser que permanece fiel a un arcano que no ha elegido, la certeza de partir o de ser abandonado en la muerte, allí donde sin saber si respecto a su íntimo complementador será el primer o segundo arribante, allí este fugitivo de la normalidad cósmica, sobreviviente de una historia de separación radical, necesitará de un particular entrenamiento, del entrenamiento más importante para el ser humano, a saber, aquel necesario para soportar la partida de los próximos más queridos, sobrevivir a la pérdida del compañero íntimo, el abandono del "complementador imprescindible" (Vásquez Rocca 2007). El ser humano es el animal que ha de esperar y sobrevivir a las separaciones de sus próximos.

Sloterdijk sostiene en este punto que con el desarrollo de una teoría de la existencia complementada -o de de los genios- se puede hacer justicia al interés de Heidegger por el enraizamiento, extrayendo o recuperando de las nociones esbozadas por Heidegger tanto cuanto sea posible.

De esta forma, el proyecto Esferas puede entenderse también como un intento de hacer visible -al menos en un aspecto esencial- el proyecto Ser y espacio, subtemáticamente implícito en la obra temprana de Heidegger. Este proyecto es, sin duda, como lo indica el subtítulo de la obra de Carla Cordua, una recepción filosófica. Una carta que ha encontrado un destinatario en cuyas manos el mensaje cifrado se ha convertido en un legado fructífero.

\section{Referencias bibliográficas}

Cordua, Carla (2008), Sloterdijk y Heidegger; La recepción filosófica. Santiago de Chile: Ediciones Universidad Diego Portales.

Sloterdijk, Peter (2001), Nicht gerettet: Versuche nach Heidegger. Frankfurt a. M.: Suhrkamp.

(2003a), Crítica de la razón cínica. Traducido del alemán. Madrid: Siruela. 2 vols.

(2003b), Esferas I, Burbujas. Traducido del alemán. Madrid: Siruela. 
(2004), Esferas II, Globos. Traducido del alemán. Madrid: Siruela.

(2007), En el mundo interior del capital, para una teoría filosófica de la globalización. Traducido del alemán. Madrid: Siruela.

Sloterdijk, Peter y Hans-Jürgen Heinrichs (2004), El sol y la muerte; Investigaciones dialógicas. Traducido del alemán. Madrid: Siruela.

Vásquez Rocca, Adolfo (2007). "Sloterdijk; espacio tanatológico, duelo esférico y disposición melancólica", La Lámpara de Diógenes. 8:179-188 (http://www. ldiogenes.buap.mx/revistas/14/179.pdf).

(2008a), "Peter Sloterdijk: Temblores de aire, atmoterrorismo y crepúsculo de la inmunidad". Nómadas. 17: 159-168 (http://www.ucm.es/info/ nomadas/17/avrocca_sloterdijk3.pdf).

(2008b). "Sloterdijk y Heidegger; Metáfora de la navegación, hiperpolítica y crítica del imaginario filoagrario", en Vásquez Rocca, Peter Sloterdijk; esferas, helada cósmica y políticas de climatización. València: Edicions Alfons el Magnànim, pp. 99-112. 